\title{
Statistical Analysis of the Relation between Fire Occurrence and Weather Factors
}

\author{
Dong-Woo Song ${ }^{\# 1}$, Ki-Sung Kim ${ }^{\# 2}$, Su-Kyung Lee ${ }^{\# 3}$ \\ \# Department of Safety Engineering, Seoul National University of Science and Technology \\ 232, Gongneung-ro, Nowon-gu, Seoul, Korea \\ 1dw5007@seoultech.ac.kr \\ 2albali85@seoultech.ac.kr \\ ${ }^{3}$ lsk@seoultech.ac.kr
}

\begin{abstract}
The living conditions and environment of humans change depending on the climate. In Korea, the number of fires changes continuously with the seasons. In this study, we quantitatively analyzed fire occurrence trends and determined the relationship between fire occurrences and weather information. We verified the relationship between the weather and fire occurrences by using preprocessed data to obtain the hourly frequency of fire occurrence for each weather factor. We divided the frequency of fire occurrence by the number of hours within each range according to the weather. By analyzing the relations between different types of fire data (e.g., the fire type, source of ignition, cause of ignition, and material that first ignited) and the weather data, we obtained trends indicating the relation between each weather variable and each fire variable. Our results can help with understanding the influence of weather on fire occurrences and thus help prevent weather-related fire occurrences.
\end{abstract}

Keyword - Weather factor, Hourly frequency of fire occurrence, Scatter graph, Jonckheere-Terpstra test

\section{INTRODUCTION}

In Korea, over 40,000 cases of accidental fires occur each year, resulting in at least 2000 deaths. These fires have similar root causes [1]. The most efficient way to reduce the occurrence of fatal fires is to improve the prediction of fire incidents.

By using information regarding factors that directly affect fires (e.g., the presence of flammable materials, ignition sources, and fire-protection facilities) and indirectly affect their occurrence (e.g., lifestyle patterns, social environment, economy, and weather), we can predict the fire risk.

The quality of life and culture are significantly affected by climatic and weather conditions. In this paper, climatic conditions refer to meteorological statistics, which are the statistical characteristics of weather for a given region and time period [2]. In Korea, the climate is temperate in nature with four distinctive seasons, including a hot and humid summer and a cold and dry winter. Depending on the climatic characteristics, the living environment for humans changes periodically. The number of fires tends to decrease during the summer and increase in the winter; this confirms the effect of the season on fire occurrences. Thus, meteorological phenomena have the potential to significantly affect human life [3].

Holmes et al. [4] used statistics and data-mining techniques to determine variations in the fire-occurrence rate for chimney fires with changes in the temperature and weather. They showed that chimney fires clearly increased with decreasing temperature to confirm a seasonal influence and that the temperature has a slightly nonlinear relation. Therefore, weather may directly or indirectly affect the risk of fire through its effect on human life.

In this study, we investigated the nature of trends between fire occurrences and weather information because of their close relations to human life and the environment.

\section{RESEARCH PROCEDURE}

Figure 1 shows the procedure that we employed in this study to examine the characteristics of the data used. Here, we present the methods used for the collection and preprocessing of the data. We considered the concept of the relative frequency of the hourly fire occurrence in order to analyze the relationship between the weather information and fires. Based on this concept, we analyzed the trends for each weather variable and the fire occurrence. 


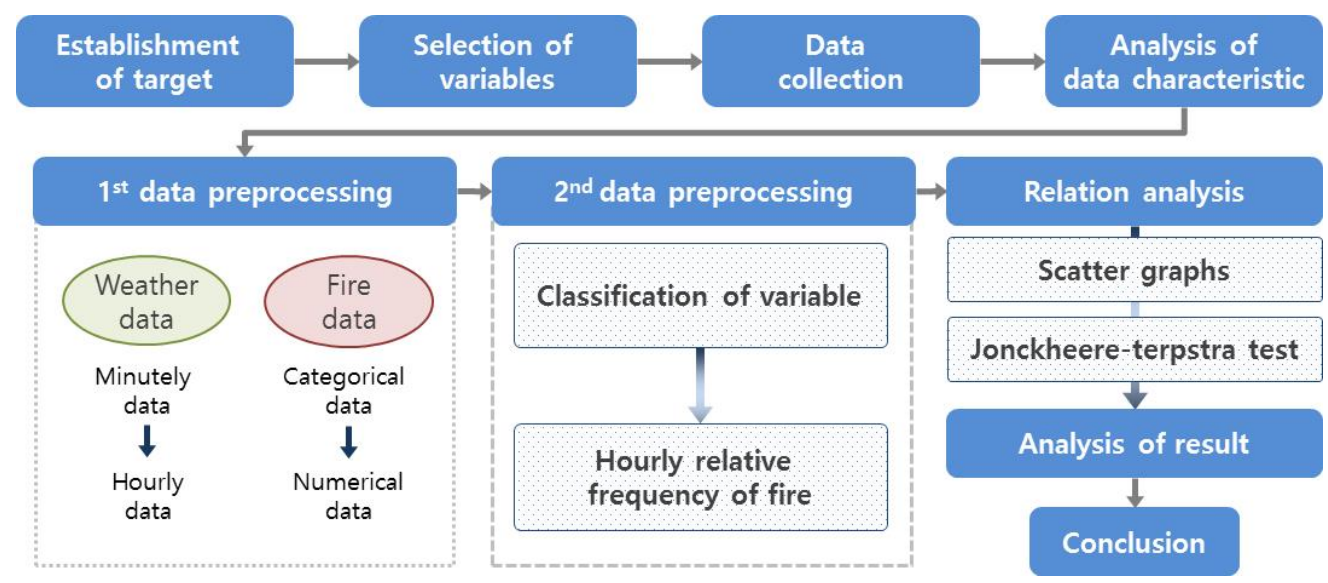

Fig. 1. Flow diagram used in study.

\section{Data Collection}

\section{A. Definition of Collected Data}

Table 1 presents the types of weather data, which we used as the independent variables, and the fire investigation data, which were the dependent variables. For the fire cause analysis, we selected the fire type, source of ignition, material that first ignited, and cause of ignition as representative fire data variables.

TABLE I. Types of variables

\begin{tabular}{|l|l|l|}
\hline Variable & Variable type \\
\hline \multirow{3}{*}{$\begin{array}{l}\text { Weather data (Independent } \\
\text { variable) }\end{array}$} & Humidity & Numerical data \\
\cline { 2 - 3 } & Temperature & Numerical data \\
\cline { 2 - 3 } & Wind speed & Numerical data \\
\hline \multirow{3}{*}{$\begin{array}{l}\text { Fire investigation data } \\
\text { (Dependent variable) }\end{array}$} & Fire type & Numerical data \\
\cline { 2 - 3 } & Source of ignition & Numerical data \\
\cline { 2 - 3 } & Material first ignited & Numerical data \\
\cline { 2 - 3 } & Cause of ignition & Numerical data \\
\hline
\end{tabular}

\section{B. Weather Data}

To collect the weather data observed over the same period as the fire investigation data, we used a Web crawler to collect minute-by-minute historical weather data acquired from an automatic weather station (AWS) [5] operated by the Korea Meteorological Administration [6]. For each AWS, we obtained parameters such as the AWS location code, humidity, temperature, wind speed, and precipitation.

We obtained historical weather data for 16 cities that fell under the jurisdiction of the fire department. We selected districts in which city or provincial offices are located as representative observation locations. Table 2 presents the representative weather stations and fire departments for the areas considered in the analysis. 
TABLE II. Observatories for weather data collection in each fire department region

\begin{tabular}{|l|l|}
\hline Fire department region & Weather station \\
\hline Gangwon fire headquarters & Chuncheon \\
\hline Gyeonggido 2nd fire headquarters & Munsan \\
\hline Gyeonggido fire headquarters & Suwon \\
\hline Gyeongsangnamdo fire department & Changwon \\
\hline Gyeongbuk fire service headquarters & Andong \\
\hline Gwangju fire department & Gwangju \\
\hline Daegu fire department & Daegu \\
\hline Daejeon fire department & Daejeon \\
\hline Pusan fire department & Pusan \\
\hline Seoul metropolitan fire and disaster headquarters & Seoul \\
\hline Ulsan fire department & Ulsan \\
\hline Incheon fire and safety management department & Incheon \\
\hline Jeonbuk fire headquarters & Jeonju \\
\hline Jeju fire safety headquarters & Jeju \\
\hline Chungbuk fire service headquarter & Chungju \\
\hline Chungnam fire service headquarter & Buyeo \\
\hline
\end{tabular}

\section{Fire Investigation Data}

In Korea, fire-investigation data have been collected systematically since the development of the national fire information system in 2007. In the study, we used fire investigation data provided by the Fire Service Bureau of the Ministry of Public Security in Korea for the period of 2007-2012 [1, 7-11]. We analyzed representative variables of fire causes, such as the fire type, ignition source, first material ignited, and cause of ignition. Table 3 classifies the dependent variables obtained in this study [12].

\section{Data Categorization}

We categorized continuous data for use in the analysis. To calculate the frequency of the hourly fire occurrence as proposed in this study, the data needed to be categorized for analysis.

We used the Jenks natural breaks optimization method as the theoretical basis for categorizing the data. The advantage of the Jenks method is that the boundaries of the optimized level interval can be established according to the desired number of levels. Table 4 classifies the weather data used in this study.

TABLE III. Fire data used for research

\begin{tabular}{|l|l|}
\hline Categories & $\begin{array}{l}\text { Building structure, ship, aerial vehicle, hazardous material and gas manufactory, } \\
\text { forests, fields, automobile, railway vehicle, miscellaneous (waste material, etc.) }\end{array}$ \\
\hline Fire type & $\begin{array}{l}\text { Cigarette, lighter, friction, conduction, radiation, flame, sparks, spontaneous } \\
\text { combustion, actuated equipment, explosive, firecracker, chemical combustion, } \\
\text { miscellaneous, unknown }\end{array}$ \\
\hline Material first ignited & $\begin{array}{l}\text { Furniture, flammable gas, signboard, awning, food, garbage, hazardous material } \\
\text { etc., automobile, railway vehicle, ship, aircraft, electrical, electronics, paper, } \\
\text { wood, hay, bedding, other textiles, synthetic resins, miscellaneous, unknown }\end{array}$ \\
\hline Cause of ignition & $\begin{array}{l}\text { Gas leak, explosion, traffic accident, mechanical factor, careless, natural factor, } \\
\text { electrical factor, chemical factor, miscellaneous, unknown }\end{array}$ \\
\hline
\end{tabular}

TABLE IV. Classification of variable-related weather information

\begin{tabular}{|l|l|}
\hline Variable & Ranges of classification \\
\hline Relative humidity $(\%)$ & Below 37, 37-54, 54-69, 69-83, above 83 \\
\hline Temperature $\left({ }^{\circ} \mathrm{C}\right)$ & Below $0,0-8,8-16,16-23$, above 23 \\
\hline Wind velocity $(\mathrm{m} / \mathrm{s})$ & Below $1,1-2.1,2.1-3.5,3.5-5.4$, above 5.4 \\
\hline
\end{tabular}




\section{Statistical Analysis Methods}

In the analysis process, the previously selected weather-related independent variables had a one-to-one relation with the fire data, which were dependent variables. We defined the concept of the relative frequency of hourly fire occurrence and plotted scatter graphs to analyze the trends observed with the J-T test.

Table 5 presents the concept of the frequency of hourly fire occurrence; it shows the absolute and relative frequencies as well as the absolute frequency and relative frequency of hourly fire occurrence. In the general frequency analysis, we found the fire occurrence to be greatest when the humidity was $37 \%-54 \%$. However, if the frequency of hourly fire occurrence is analyzed depending on the weather condition, the fire occurrence may be greatest when the humidity is $37 \%$ or less. By considering this concept, the probability of fire occurrence can be obtained according to both the relevant region's weather and the trend of the fire occurrence depending on the weather. The frequency of hourly fire occurrence is expressed as the relative frequency of the hourly fire occurrence and was used for the final comparative analysis between districts. The relative frequency is the rate of each category's frequency against the frequency of all the categories and uses the probabilistic concept.

The proposed formula is based on the concept shown in Table 5 and is given in Eq. (1):

$$
F_{W}=\frac{\sum_{W=i}^{i} N\left(F_{W}\right)}{\sum_{W=i}^{i} N\left(t_{W}\right)}
$$

where $F_{w}$ is the frequency of the hourly fire occurrence when the dependent variable is within the range $w$, $N\left(F_{w}\right)$ is the fire occurrence frequency within the range $w$, and $N\left(t_{w}\right)$ is the hours of observed weather data in the range $w$.

Figure 2 shows scatter graphs of the (a) absolute frequency of the fire occurrence, (b) relative frequency of the fire occurrence, (c) absolute frequency of the hourly fire occurrence, and (d) relative frequency of the hourly fire occurrence within the range of humidity values for all fires in 2007-2012. The absolute frequency of the fire occurrence was high within the distribution range of the relative humidity. However, as the actual humidity increased, the frequency of the hourly fire occurrence gradually decreased. The relative frequency of the hourly fire occurrence showed similar trends for each district. This may mean that the relative humidity is a contributing factor to the fire occurrence. By considering the concept of the relative frequency of hourly fire occurrence, we analyzed the trend between the meteorological information and fire occurrence.

We used the J-T test for the trend analysis, which we conducted by using SPSS software. When the number of samples was less than 10, the amount of data was too small for normality to be accepted, so we used a nonparametric statistical method. After grouping the districts, we used the J-T test to analyze the weather data trends of the relative frequency of the hourly fire occurrence.

The $\mathrm{J}-\mathrm{T}$ test is a nonparametric method that is employed to verify whether dependent variables are increasing or decreasing following changes in the quantities of independent variables. Figure 3 shows the same concept: independent variables of three or more groups have ranks, and the test is a type of trend analysis that verifies whether the value of a dependent variable increases or decreases with an increasing rank of an independent variable [13].

TABLE V. Concept and method employed to obtain hourly frequency of fire occurrence

\begin{tabular}{|c|c|c|c|c|c|}
\hline Categories & $\begin{array}{c}\text { Absolute } \\
\text { frequency of fire }\end{array}$ & $\begin{array}{c}\text { Relative } \\
\text { frequency of fire }\end{array}$ & $\begin{array}{c}\text { Number of } \\
\text { weather data }^{* *}\end{array}$ & $\begin{array}{l}\text { Hourly absolute } \\
\text { frequency of fire }\end{array}$ & $\begin{array}{l}\text { Hourly relative } \\
\text { frequency of fire }\end{array}$ \\
\hline $0-37$ & 7,313 & 0.20 & 7,928 & $\begin{array}{c}7,313 / 7,928= \\
0.922\end{array}$ & 0.27 \\
\hline $37-54$ & 9,689 & 0.27 & 12,718 & $\begin{array}{c}9,689 / 12,718= \\
0.762\end{array}$ & 0.22 \\
\hline $54-69$ & 8,547 & 0.23 & 13,093 & $\begin{array}{c}8,547 / 13,093= \\
0.653\end{array}$ & 0.19 \\
\hline 69-83 & 5,849 & 0.16 & 10,080 & $\begin{array}{c}5,849 / 10,080= \\
0.580\end{array}$ & 0.17 \\
\hline $83-100$ & 4,919 & 0.14 & 8,789 & $\begin{array}{c}4,919 / 8,789= \\
0.560\end{array}$ & 0.16 \\
\hline Total & 36,317 & 1.00 & 52,608 & 3.477 & 1.00 \\
\hline
\end{tabular}

*Absolute frequency of fire: $2007^{\text {th }} \sim 2012^{\text {th }}$ year, Fire data

$* *$ Number of weather data: $2007^{\text {th }} \sim 2012^{\text {th }}$ year, Hourly observed weather data 


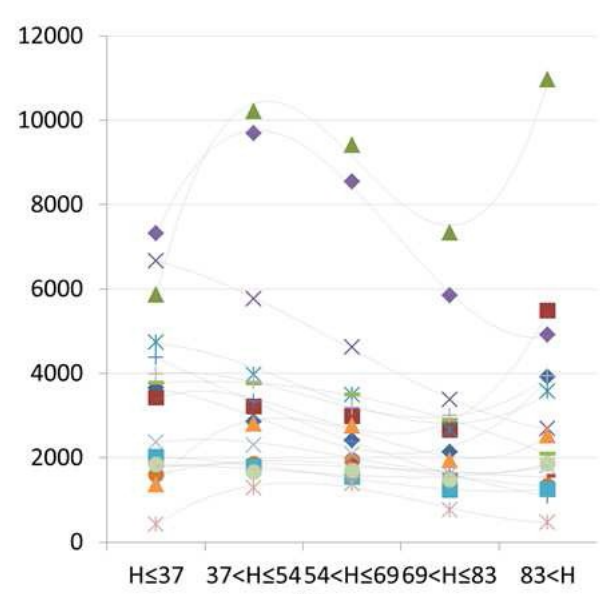

(a)

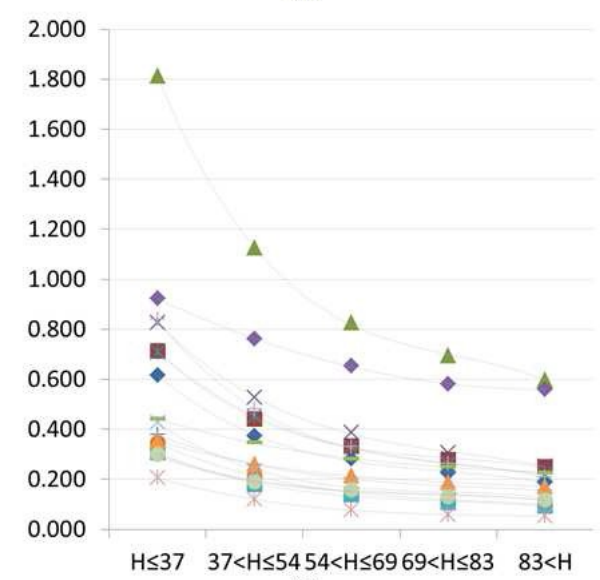

(c)

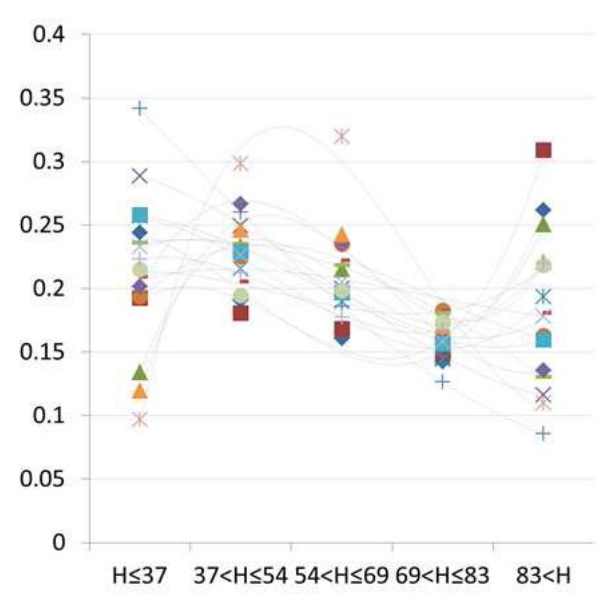

(b)

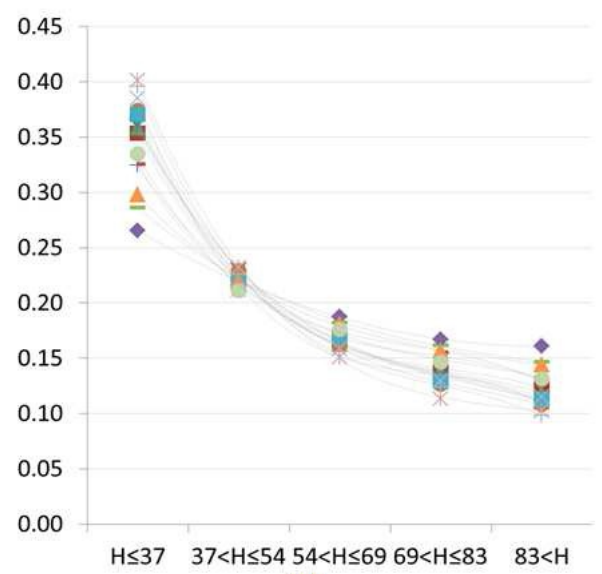

(d)

Fig. 2. Scatter graphs: (a) absolute frequency of fire occurrence, (b) relative frequency of fire occurrence, (c) hourly absolute frequency of fire occurrence, and (d) hourly relative frequency of fire occurrence.

Group 1
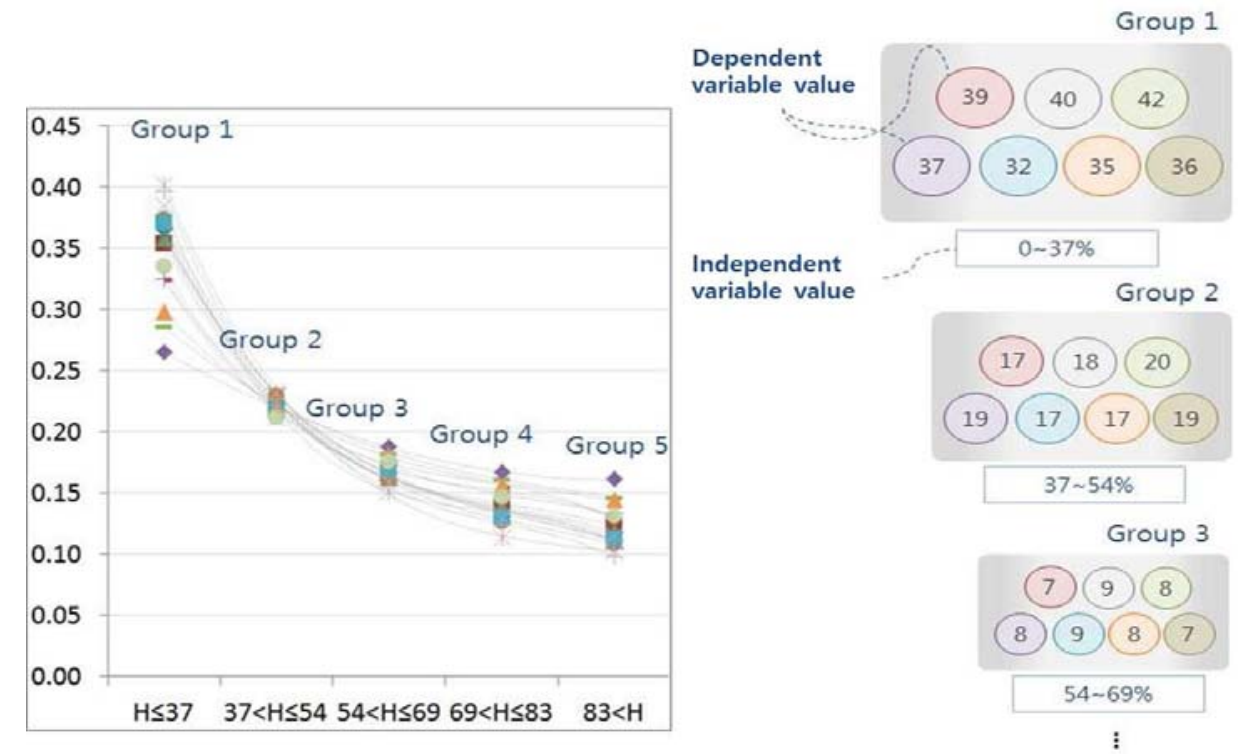

Fig. 3. Concept of Jonckheere-Terpstra test. 


\section{RESULTS}

\section{A. Relation between the Fire Occurrence and Relative Humidity}

Figure 4 graphs the results of the relation analysis for all fire occurrences depending on the relative humidity. Figure 4(b) shows that the relative frequency of the hourly fire occurrence decreased with increasing humidity. The results of the J-T test were statistically significant with the standardization J-T statistics being -11.101 and the approximate significant probability being 0.05 or less. Based on the $\mathrm{J}-\mathrm{T}$ test results for the relative humidity and each variable, the approximate significant probability was 0.05 or less with the relative humidity. Most of the variables detailed in Table 6 were observed, so there is a definite trend. The analytical results for variables such as the fire type, source of ignition, cause of ignition, and material first ignited showed that the humidity is inversely proportional to the relative frequency of the hourly fire occurrence for most variables.

The J-T test results for each variable showed that most tended to decrease with increasing relative humidity. When the material that first ignited was electrical or electronic, this trend was not clearly observed because the approximate significant probability exceeded 0.05. All of the other variables showed trends where the probability was 0.05 or less. In the J-T test results for the fire type and relative humidity, the standardization J$\mathrm{T}$ statistics were negative, so the relative frequency of the hourly fire occurrence decreased with increasing relative humidity.

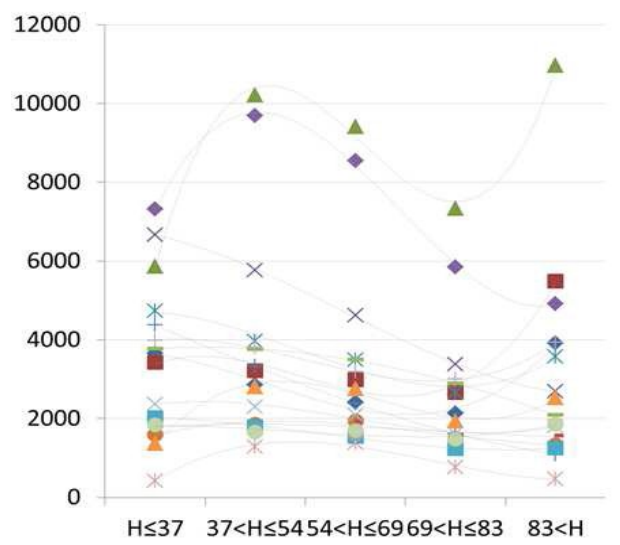

(a)

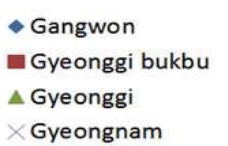

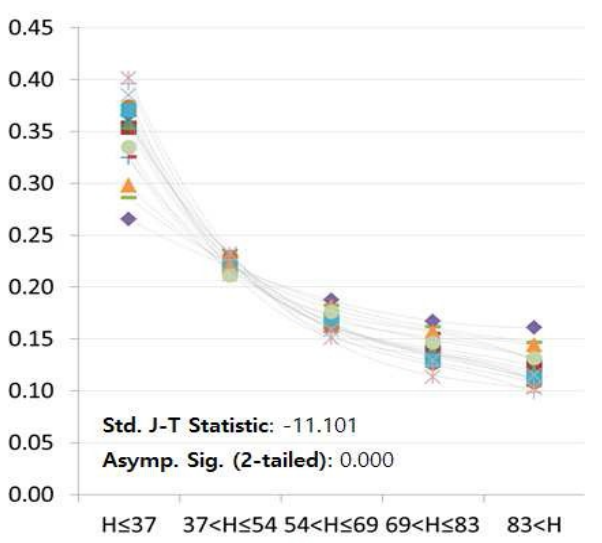

(b)

$\begin{array}{ll}\text { - Busan } & \text { Jeonbuk } \\ \text { - Seoul } & \text { Jeju } \\ \text { EUlsan } & \text { Chungbuk } \\ \Delta \text { Incheon } & \text { Chungnam }\end{array}$

Fig. 4. Fire occurrence according to relative humidity: (a) absolute frequency and (b) hourly relative frequency.

When the sources of ignition were spontaneous combustion and chemical combustion, the relative frequency of the hourly fire occurrence increased with the relative humidity. For the other variables, the relative frequency of the hourly fire occurrence decreased with increasing relative humidity.

When the causes of ignition were traffic accidents and natural factors, the relative frequency of the hourly fire occurrence increased with the relative humidity. For the other variables, the relative frequency of the hourly fire occurrence decreased with increasing relative humidity.

Finally, in the case of the material first ignited, the standardization $\mathrm{J}-\mathrm{T}$ statistics for all variables were negative. Thus, the relative frequency of the hourly fire occurrence decreased with increasing relative humidity. 
TABLE VI. Jonckheere-Terpstra test results with humidity and fire as variables

\begin{tabular}{|lrr|}
\hline Variable & Std. J-T statistic & Asymp. sig.(two-tailed) \\
\hline Fire type & & \\
\hline Building structure & -10.352 & 0.000 \\
Miscellaneous (waste material, etc.) & -10.386 & 0.000 \\
Forests, fields & -10.556 & 0.000 \\
Automobile, railway vehicle & -10.233 & 0.000 \\
\hline Source of ignition & & \\
\hline Cigarette, lighter & -10.827 & 0.000 \\
Friction, conduction, radiation & -9.970 & 0.000 \\
Flame, sparks & -10.598 & 0.000 \\
Spontaneous combustion & 6.251 & 0.000 \\
Actuated equipment & -8.348 & 0.000 \\
Explosive, firecracker & -7.105 & 0.000 \\
Chemical combustion & 2.344 & 0.019 \\
\hline Cause of ignition & & 0.000 \\
\hline Gas leak, explosion & -7.660 & 0.000 \\
Traffic accident & 3.923 & 0.000 \\
Mechanical factor & -10.089 & 0.000 \\
Negligence & -10.556 & 0.000 \\
Natural factor & 6.327 & 0.000 \\
Electric factor & -4.824 & 0.020 \\
Chemical factor & -2.327 & \\
\hline Material first ignited & & 0.000 \\
\hline Furniture & -8.271 & 0.000 \\
Flammable gas & -8.696 & 0.002 \\
Signboard, awning & -3.074 & 0.000 \\
Foods & -6.964 & 0.000 \\
Waste material & -10.751 & 0.000 \\
Hazardous material & -9.384 & 0.000 \\
Automobile, railway vehicle, ship, aircraft & -8.849 & 0.373 \\
Electrical, electronics & -0.892 & 0.000 \\
Paper, wood, hay & -10.564 & 0.000 \\
Bedding, other textiles & -10.556 & 0.000 \\
Synthetic resins & -10.275 & \\
& & \\
\hline
\end{tabular}

\section{B. Relation between the Fire Occurrence and Temperature}

Figure 5 graphs the results of the relation analysis for all fire occurrences depending on the temperature. We identified similar trends between the relative frequency of the hourly fire occurrence and the temperature for different regional groups. The results of the $\mathrm{J}-\mathrm{T}$ test were statistically significant: the standardization $\mathrm{J}-\mathrm{T}$ statistics were -4.824 , and the approximate significant probability was 0.05 or less.

According to the J-T test results, the approximate significant probability was 0.05 or less between the temperature and most of the variables, as indicated in Table 7. The analysis for variables such as the fire type, source of ignition, cause of ignition, and material first ignited showed different trends for each variable.

For the building structure, which is a fire-type variable, the standardization $\mathrm{J}-\mathrm{T}$ statistics were negative. Thus, the relative frequency of the hourly fire occurrence decreased with increasing temperature. For miscellaneous (waste material, etc.) and forests, the standardization $\mathrm{J}-\mathrm{T}$ statistics were positive. Thus, the relative frequency of the hourly fire occurrence increased with the temperature.

When the sources of ignition were friction, conduction, radiation, unknown, and actuated equipment, the relative frequency of the hourly fire occurrence decreased with increasing temperature. For the other variables, the relative frequency of the hourly fire occurrence also decreased with increasing temperature. 
When the causes of ignition were natural and chemical factors, the relative frequency of the hourly fire occurrence decreased with increasing temperature. For the other variables, the relative frequency of the hourly fire occurrence also decreased with increasing temperature. When the materials first ignited were signboards, awnings, food, and waste, the relative frequency of the hourly fire occurrence decreased with increasing temperature. For the other variables, the relative frequency of the hourly fire occurrence also decreased with increasing temperature.

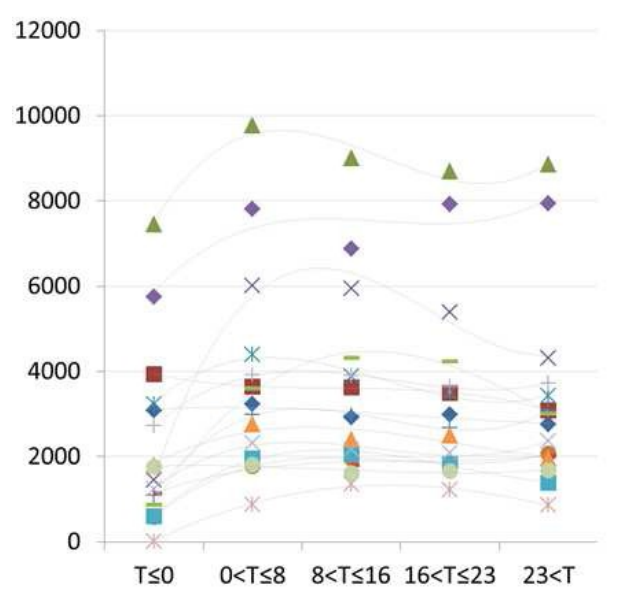

(a)

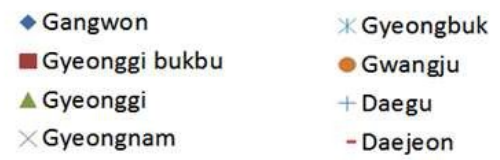

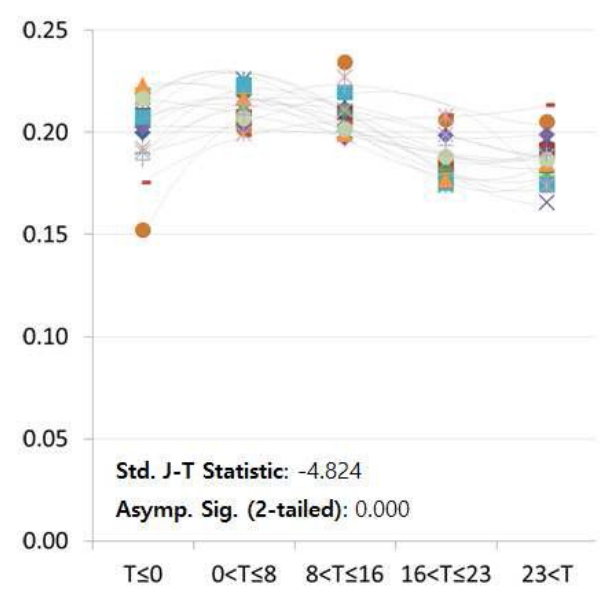

(b)

$\begin{array}{ll}\text { - Busan } & \text { Jeonbuk } \\ \text { - Seoul } & \text { Jeju } \\ \text { wUlsan } & \text { Chungbuk } \\ \text { A Incheon } & \text { Chungnam }\end{array}$

Fig. 5. Fire occurrence according to temperature: (a) absolute frequency and (b) hourly relative frequency.

TABLE VII. Jonckheere-Terpstra test results with temperature and fire as variables

\begin{tabular}{|lrr|}
\hline Variable & Std. J-T statistic & Asymp. sig.(two-tailed) \\
\hline Fire type & & \\
\hline Building structure & -4.085 & 0.000 \\
Miscellaneous (waste material etc.) & 3.083 & 0.002 \\
Forests, fields & 3.957 & 0.000 \\
Automobile, railway vehicle & 0.110 & 0.912 \\
\hline Source of ignition & & \\
\hline Cigarette, lighter & 2.794 & 0.005 \\
Friction, conduction, radiation & -3.652 & 0.000 \\
Flame, sparks & -0.017 & 0.986 \\
Spontaneous combustion & 6.355 & 0.000 \\
Actuated equipment & -4.000 & 0.000 \\
Explosive, firecracker & 3.396 & 0.001 \\
Chemical combustion & 2.412 & 0.016 \\
\hline Cause of ignition & & \\
\hline Gas leak, explosion & -1.359 & 0.174 \\
Traffic accident & -3.703 & 0.000 \\
Mechanical factor & -3.669 & 0.000 \\
Negligence & 1.775 & 0.076 \\
Natural factor & 5.479 & 0.000 \\
Electric factor & -4.569 & 0.000 \\
Chemical factor & 3.095 & 0.002 \\
\hline Material first ignited & & 0.003 \\
\hline Furniture & -3.015 & 0.070 \\
Flammable gas & -1.809 &
\end{tabular}




\begin{tabular}{lrr} 
Signboard, awning & 2.624 & 0.009 \\
Foods & 4.688 & 0.000 \\
Waste material & 3.643 & 0.000 \\
Hazardous material & 0.246 & 0.805 \\
Automobile, railway vehicle, ship, aircraft & 0.085 & 0.932 \\
Electrical, electronics & -2.904 & 0.004 \\
Paper, wood, hay & 0.263 & 0.792 \\
Bedding, other textiles & -3.898 & 0.000 \\
Synthetic resins & -4.560 & 0.000 \\
\hline
\end{tabular}

\section{Relation between the Fire Occurrence and Wind Velocity}

Figure 6 graphs the results of the relation analysis for all fire occurrences depending on the wind velocity. Figure 6(b) shows that the relative frequency of the hourly fire occurrence increased with the wind velocity. The $\mathrm{J}-\mathrm{T}$ test results were statistically significant: the standardization $\mathrm{J}-\mathrm{T}$ statistics were 9.579 , and the approximate significant probability was 0.05 or less.

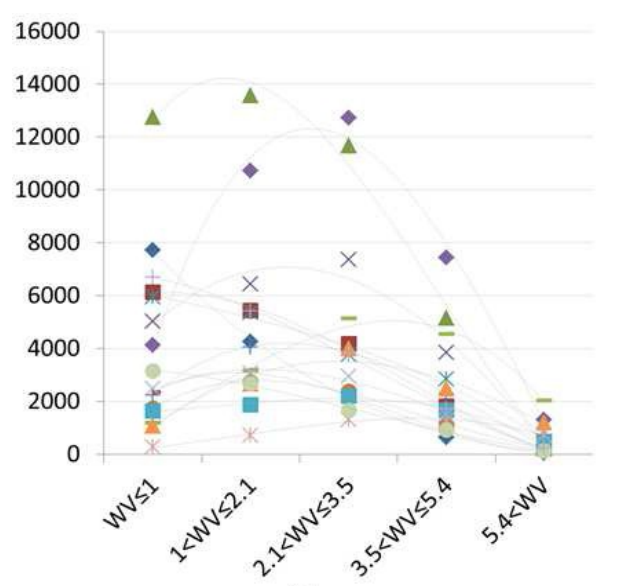

(a)

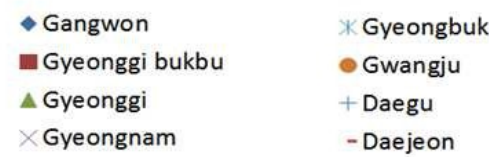

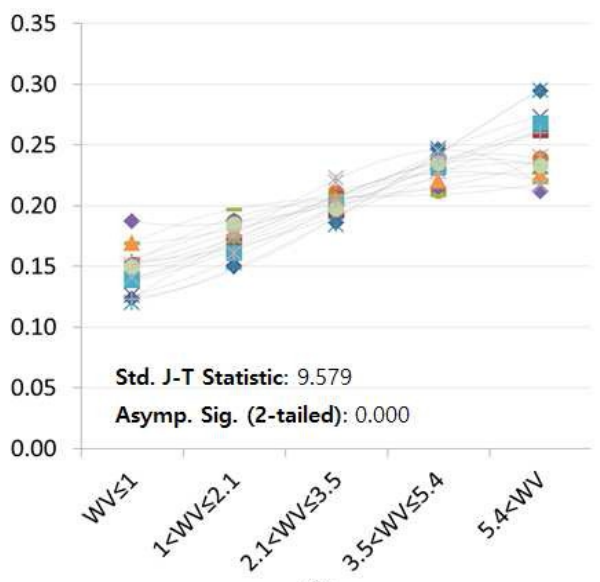

(b)

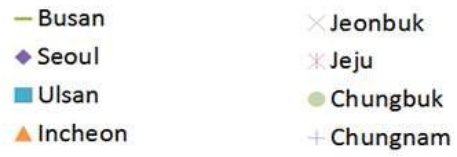

Fig. 6. Fire occurrence according to wind velocity: (a) absolute frequency and (b) hourly relative frequency.

TABLE VIII. Jonckheere-Terpstra test results with wind velocity and fire as variables

\begin{tabular}{|lcr|}
\hline Variable & Std. J-T statistic & Asymp. sig. (two-tailed) \\
\hline Fire type & & \\
\hline Building structure & 9.970 & 0.000 \\
Miscellaneous (waste material, etc.) & 9.146 & 0.000 \\
Forests, fields & 9.987 & 0.000 \\
Automobile, railway vehicle & 5.528 & 0.000 \\
\hline Source of ignition & & 0.000 \\
\hline Cigarette, lighter & 9.137 & 0.000 \\
Friction, conduction, radiation & 6.208 & 0.000 \\
Flame, sparks & 9.808 & 0.000 \\
Spontaneous combustion & 5.028 & 0.000 \\
Actuated equipment & 9.163 & 0.231 \\
Explosive, firecracker & 1.197 & 0.054 \\
Chemical combustion & -1.924 & 0.396 \\
\hline Cause of ignition & & 0.000 \\
\hline Gas leak, explosion & 0.850 & \\
Traffic accident & -4.586 &
\end{tabular}




\begin{tabular}{|lcr|} 
Mechanical factor & 4.968 & 0.000 \\
Negligence & 9.426 & 0.000 \\
Natural factor & 4.901 & 0.000 \\
Electric factor & 8.416 & 0.000 \\
Chemical factor & 0.484 & 0.628 \\
\hline Material first ignited & & 0.003 \\
\hline Furniture & 3.006 & 0.006 \\
Flammable gas & 2.760 & 0.653 \\
Signboard, awning & -0.450 & 0.114 \\
Foods & 1.580 & 0.000 \\
Waste material & 8.730 & 0.000 \\
Hazardous material & 4.484 & 0.000 \\
Automobile, railway vehicle, ship, aircraft & 4.051 & 0.000 \\
Electrical, electronics & 7.923 & 0.000 \\
Paper, wood, hay & 9.571 & 0.000 \\
Bedding, other textiles & 5.189 & 0.000 \\
Synthetic resins & 8.101 & \\
\hline
\end{tabular}

According to the results of the $\mathrm{J}-\mathrm{T}$ test between the wind velocity and each variable, the approximate significant probability was 0.05 or less as the wind velocity changed. Most variables, such as the fire type, source of ignition, cause of ignition, and material first ignited, showed a positive relation between the wind velocity and relative frequency of the hourly fire occurrence, as indicated in Table 8.

The J-T test results showed an increasing trend between the wind velocity and most of the variables. There were no trends when the sources of ignition were explosives, firecrackers, and chemical combustion; the causes of ignition were chemicals, signboards, and awnings; and the materials first ignited were foods because the approximate significant probability exceeded 0.05 . All of the other variables showed this trend because the probability was 0.05 or less.

For the $\mathrm{J}-\mathrm{T}$ test results between the fire type and wind velocity, the standardization $\mathrm{J}-\mathrm{T}$ statistics were negative, so the relative frequency of the hourly fire occurrence increased with the wind velocity.

For all variables, when the sources of ignition were explosives, firecrackers, and chemical combustion, the relative frequency of the hourly fire occurrence increased with the wind velocity.

When the cause of ignition was traffic accidents, the relative frequency of the hourly fire occurrence decreased with increasing wind velocity. For other variables, the relative frequency of the hourly fire occurrence increased with the wind velocity.

Finally, when the materials first ignited were signboards, awnings, and foods, the relative frequency of the hourly fire occurrence increased with the wind velocity.

\section{Discussion}

The analysis showed that most dependent variables were influenced by weather factors. The effects on outdoor fires were especially significant.

With respect to the humidity, the results were unique for natural combustion (source of ignition) and natural causes (cause of ignition): while there was no relation found between districts, the fire occurrence increased with the humidity. We observed such trends for natural causes because fires occur more frequently upon the occurrence of thunder and lightning than other natural disasters. For the temperature, while no clear trend was observed as in the case of the humidity, each variable showed several kinds of trends.

When the fire type was miscellaneous, the cause of ignition was negligence, the sources of ignition were flame, sparks, and tobacco and lighter flames, and the material first ignited was waste, they all had high fire occurrence rates for the same middle temperature range. This is believed to be because of human activity within this temperature range. The reason for friction, conduction, radiation (source of ignition), motor equipment (source of ignition), electric cause (cause of ignition), mechanical cause (cause of ignition), and electrical and electronics (material first ignited) having high rates of fire occurrence at low or high temperatures was determined to be the seasonal influence. Many variables showed trends where the fire occurrence increased with the wind speed. The trends for outdoor fires such as forestry and waste fires were clearer than those for indoor fires such as building structures. 


\section{CONCLUSIONS}

In this study, we analyzed fire occurrence trends based on weather information.

We categorized and used continuous data to determine the hourly frequency of fire occurrence. This study is useful in that it highlights the relationship between the weather and fire occurrences by using a differentiated data preprocessing procedure.

By analyzing the relationship between different types of fire data (e.g., the fire type, fire source, fire cause, and first material ignited) and weather data, we obtained trends showing the relation between variables of each weather pattern and each fire variable. For the humidity, we found that fires occur more frequently with decreasing humidity. With respect to the temperature, we observed various trends for different independent and dependent variables. The fire occurrence was found to increase with the wind speed.

Based on such observed trends, understanding the relation between weather and fire occurrence is very important. These results can be utilized to understand the influence of weather on specific types of fires and to prevent fires that may occur because of weather conditions.

The limitations of our study involve possible errors between the weather at the measurement point and fire occurrence point because the weather at these two locations does not match exactly. If accurate weather data are provided, the reliability of the analysis would be further increased.

\section{REFERENCES}

[1] Fire Service Bureau, National Emergency Management Agency, 2012. Fire statistics data. National Emergency Management Agency, Seoul

[2] Oh SN, Kim JW, Lee TY, Shin IC, Lee GS, An SI, 2011. Climate and culture. Sigmapress, Seoul

[3] Aguado E, Burt JE, 2004. Understanding weather and climate. Pearson Education, Upper Saddle River, NJ

[4] Holmes M, Wang Y, Ziedins I, 2009. The application of data mining tools and statistical techniques to identify patterns and changes in fire events. The University of Auckland, Auckland

[5] Korea Meteorological Services, Automatic Weather Station, 2006 http://203.247.66.10/weather/observation/aws_table_popup.jsp. Accessed 1 July 2013

[6] Ryu JW, Lee SK, Shin DI et al., 2014 Development of a fire precursor alarm system based on fire investigation data mining, Korea National Emergency Management Agency, Seoul

[7] Fire Service Bureau, National Emergency Management Agency, 2007. Fire statistics data. National Emergency Management Agency, Seoul

[8] Fire Service Bureau, National Emergency Management Agency, 2008. Fire statistics data. National Emergency Management Agency, Seoul

[9] Fire Service Bureau, National Emergency Management Agency, 2009. Fire statistics data. National Emergency Management Agency, Seoul

[10] Fire Service Bureau, National Emergency Management Agency, 2010. Fire statistics data. National Emergency Management Agency, Seoul

[11] Fire Service Bureau, National Emergency Management Agency, 2011. Fire statistics data. National Emergency Management Agency, Seoul

[12] Fire Service Bureau, National Emergency Management Agency, 2006. National fire classification system manual. National Emergency Management Agency, Seoul

[13] Bae JM, 2012. An illustrated guide to medical statistics using SPSS. Hannarae Academy, Seoul

\section{AUTHOR PROFILE}

Dong-Woo Song is working as Researcher at Safety Science Research Institute in Seoul National University of Science and Technology (KOREA).

Ki-Sung Kim is pursuing PhD in Seoul National University of Science and Technology (KOREA).

Su-Kyung Lee is working as Professor in Seoul National University of Science and Technology (KOREA). 